\title{
Adição da parede celular de levedura (Saccharomyces cerevisiae) na dieta para frangos de corte
}

[Addition of the yeast cell wall (Saccharomyces cerevisiae) in the diet for broilers chickens]

\author{
D.C. Barroso ${ }^{1}$, A.A. Vieira ${ }^{2}$, C.A.R. Lima ${ }^{2}$, B.S. Trindade ${ }^{1}$, A.V.C. Gomes ${ }^{2}$, \\ M.M.S. Souza $a^{2}$, G.S.S. Corrêa ${ }^{3}$

\footnotetext{
${ }^{1}$ Aluno de pós-graduação - Instituto de Zootecnia - UFRRJ - Seropédica, RJ

${ }^{2}$ Universidade Federal Rural do Rio de Janeiro - UFRRJ - Seropédica, RJ

${ }^{3}$ Universidade Federal de Mato Grosso - UFMT - Cuiabá, MT
}

\begin{abstract}
RESUMO
Os efeitos da parede celular de Saccharomyces cerevisiae (PCSc) na dieta para frangos foram avaliados com base nos tratamentos: dieta referência com avilamicina (AV); dieta referência (DR); DR com $0,1 \%$ de PCSc (PCSc0,1); DR com 0,2\% de PCSc (PCSc0,2); DR com 0,3\% de PCSc (PCSc0,3). O delineamento foi o de blocos ao acaso, com cinco tratamentos e seis repetições de 10 aves, totalizando 300 frangos, machos. No período de nove a 21 dias de idade, o tratamento PCSc0,3 influenciou negativamente no ganho de peso (631g), e no período de 34 a 39 dias, o tratamento PCSc0,1 proporcionou melhor ganho de peso $(461 \mathrm{~g})$ em relação ao tratamento com o antimicrobiano. O maior peso vivo ao abate, 2571g, foi obtido no tratamento PCSc0,1. Os pesos absolutos de sobrecoxa e coxa+sobrecoxa foram maiores nos tratamentos PCSc0,1 (290g e 560g) e PCSc0,2 (292g e 561g) e menores no tratamento PCSc0,3 (263g e 515g). Não houve influência na metabolizabilidade da ração e na contagem total de coliformes totais no íleo. Dietas com inclusão de até $0,2 \%$ de PCSc resultaram em índices produtivos adequados, podendo ser utilizadas como aditivo em dietas livres de antimicrobiano melhorador de desempenho sem o comprometimento do desempenho, características de carcaça, metabolizabilidade da ração e da contagem total de coliformes totais do íleo.
\end{abstract}

Palavras-chave: frangos de corte, prebiótico, Saccharomyces cerevisiae

\begin{abstract}
The effects of the yeast cell wall (Saccharomyces cerevisiae) (CWSc) in the diet of broiler chickens were evaluated through the following treatments: reference diet with avilamicin $(A V)$; reference diet $(R D) ; R D$ with $0.1 \%$ CWSc (CWSc0,1); RD with 0.2\% CWSc (CWSc0,2); RD with 0.3\% CWSc (CWSc0,3). The study design was randomized blocks, with five treatments and six replicates of 10 birds, totaling 300 male broilers. In the period from 9 to 21 days treatment CWSc0.3 had a negative influence on weight gain (631g) and from 34 to 39 days CWSc0.1 provided better weight gain (461g) compared to the treatment with the antimicrobial. The highest live weight value at slaughter, 2,571 grams, was obtained in treatment CWSc0.1. The absolute weights of drumstick and thigh+drumstick were higher in treatments CWSc0.1 (290g and 560g) and CWSc0.2 (292g and 561g) and were lower for CWSc0.3 (263g and 515g). There was no influence of the treatments on both the metabolizability and the total count of coliforms in the ileum. Diets until $0.2 \%$ of PCSc inclusion resulted in correct productive rates and they can be used as a ration growth promoter additive in antimicrobial free diets without damage on performance, carcass characteristics, organ weight, metabolizability of the diets and total coliform count in the ileum.
\end{abstract}

Keywords: broiler chicken, prebiotic, Saccharomyces cerevisiae

Recebido em 27 de outubro de 2011

Aceito em 9 de janeiro de 2013

E-mail: deboracostabarroso@hotmail.com 


\section{INTRODUÇÃO}

Um dos problemas que vem sendo enfrentado na produção avícola brasileira é o aumento nas restrições ao uso de antimicrobianos utilizados como aditivos zootécnicos melhoradores de desempenho na ração de frangos de corte.

A parede celular da levedura Saccharomyces cerevisiae $(\mathrm{PCSC})$ é um prebiótico que tem despertado um grande interesse devido ao seu potencial de utilização em rações de frangos. Os prebióticos são aditivos zootécnicos, equilibradores da flora intestinal, que não são digeridos e que afetam de forma benéfica o hospedeiro, pois estimulam seletivamente o crescimento e a atividade de uma ou mais bactérias benéficas do cólon e, assim, melhoram a saúde do hospedeiro (Compêndio..., 2009).

A PCSc possui como principais polissacarídeos os mananos e os glucanos, e sua estrutura é constituída por um complexo de mananoproteínas, $\beta$-glucanos e quitina. Os glucanos consistem em cadeias $\beta-1,3$ e $\beta-1,6$, sendo o $\beta$-1,3-glucano o principal componente estrutural da parede celular, responsável pela sua resistência mecânica, e os $\beta$-1,6-glucanos estão ligados a proteínas da parede celular e ao $\beta$-1,3-glucano (Klis et al., 2002). Os mananopolissacarídeos estão ligados a proteínas, formando uma camada de mananoproteínas localizada na superfície externa da parede celular da levedura (Lipke e Ovalle, 1998). A quitina constitui apenas de 1 a $3 \%$ da estrutura, porém é o componente principal do septo primário, envolvido na separação da célula-mãe da filha, sendo primordial para divisão celular (Shaw et al., 1991).

A parede celular integral de Saccharomyces cerevisiae tem sido comparada aos antimicrobianos utilizados como aditivos melhoradores do desempenho (antibióticos e quimioterápicos) por melhorar os índices produtivos (Santos et al., 2005; Godoi et al., 2008) e proporcionar benefícios ao animal em relação ao trato intestinal (Santin et al., 2001; Baurhoo et al., 2009), o que mostra ser possível a sua utilização em rações de frangos de corte, especialmente em sistemas de produção em que seja necessária a retirada dos antimicrobianos, situação esta que cria a necessidade de adição de outras substâncias que mantenham o desempenho e a saúde dos frangos.

Este experimento teve como objetivo avaliar a adição de parede celular de Saccharomyces cerevisiae na ração, a fim de investigar os efeitos no desempenho e na qualidade de carcaça de frangos de corte, na metabolizabilidade da ração e na contagem de coliformes totais no íleo, visando à possibilidade de sua utilização como alternativa aos antimicrobianos melhoradores de desempenho.

\section{MATERIAL E MÉTODOS}

Foram utilizados 300 pintos de corte Hubbard, de nove a 40 dias de idade. Até o oitavo dia de idade, os pintos foram criados com manejo convencional, sendo mantidos em círculo de proteção com campânula a gás, comedouros tipo bandeja e bebedouros tipo copo de pressão, e receberam ração balanceada à vontade, formulada de modo a atender os requerimentos nutricionais preconizados por Rostagno et al. (2005). Ao nono dia, os pintos foram pesados individualmente, a fim de se equalizar o peso inicial médio $(230 \mathrm{~g})$, e distribuídos em gaiolas metálicas de três andares, cada uma delas subdividida em dois compartimentos, cada compartimento contendo bebedouro e comedouro, sendo alojadas 10 aves por compartimento (unidade experimental). A água e a ração foram fornecidas à vontade. Durante o período de nove a 30 dias de idade, as aves foram submetidas a 24 horas de iluminação. Dos 31 aos 39 dias de idade, foi fornecida apenas a iluminação natural de, aproximadamente, 13 horas.

As rações fornecidas (Tab. 1) foram formuladas de forma a atender as exigências nutricionais para as fases inicial - nove a 21 dias -, crescimento -22 a 33 dias - e final -34 a 39 dias -, de acordo com recomendações de Rostagno et al. (2005). O delineamento experimental utilizado foi o de blocos ao acaso, sendo os andares da gaiola determinados como blocos, totalizando três blocos, cinco tratamentos e seis repetições com 10 aves por unidade experimental. 
Adição da parede celular...

Tabela 1. Composição percentual e calculada das dietas referência

\begin{tabular}{|c|c|c|c|}
\hline Ingrediente $(\%)$ & 9 a 21 dias & 22 a 33 dias & 34 a 40 dias \\
\hline Milho $(7,59 \%)$ & 57,748 & 60,309 & 64,201 \\
\hline Farelo de soja $(47,10 \%)$ & 34,769 & 31,430 & 27,649 \\
\hline Óleo de soja & 3,127 & 4,175 & 4,207 \\
\hline Fosfato bicálcico & 1,783 & 1,642 & 1,495 \\
\hline Calcário calcítico & 0,901 & 0,853 & 0,810 \\
\hline Cloreto de sódio & 0,503 & 0,478 & 0,452 \\
\hline DL-metionina & 0,249 & 0,228 & 0,224 \\
\hline L-lisina $\mathrm{HCl}$ & 0,199 & 0,189 & 0,245 \\
\hline L-treonina & 0,060 & 0,047 & 0,066 \\
\hline Suplemento mineral $^{1}$ & 0,100 & 0,100 & 0,100 \\
\hline Suplemento vitamínico ${ }^{2}$ & 0,100 & 0,100 & 0,100 \\
\hline Cloreto de colina & 0,050 & 0,040 & 0,040 \\
\hline Antioxidante BHT & 0,012 & 0,010 & 0,010 \\
\hline Caulim & 0,400 & 0,400 & 0,400 \\
\hline Total \% & 100,000 & 100,000 & 100,000 \\
\hline Nutrientes & \multicolumn{3}{|c|}{ Composição calculada } \\
\hline Energia metabolizável (Kcal/kg) & 3050 & 3150 & 3200 \\
\hline Proteína bruta $(\%)$ & 21,14 & 19,73 & 18,31 \\
\hline Cálcio $(\%)$ & 0,899 & 0,837 & 0,775 \\
\hline Fósforo disponível (\%) & 0,449 & 0,418 & 0,386 \\
\hline Sódio & 0,218 & 0,208 & 0,198 \\
\hline Lisina total $(\%)$ & 1,311 & 1,212 & 1,155 \\
\hline Lisina digestível (\%) & 1,214 & 1,122 & 1,071 \\
\hline Metionina total $(\%)$ & 0,574 & 0,535 & 0,514 \\
\hline Metionina digestível (\%) & 0,545 & 0,508 & 0,488 \\
\hline Metionina+cistina total (\%) & 0,931 & 0,873 & 0,832 \\
\hline Metionina+cistina digestível (\%) & 0,856 & 0,802 & 0,766 \\
\hline Treonina total $(\%)$ & 0,891 & 0,824 & 0,785 \\
\hline Treonina digestível (\%) & 0,787 & 0,727 & 0,692 \\
\hline Triptofano total (\%) & 0,263 & 0,243 & 0,222 \\
\hline Triptofano digestível (\%) & 0,236 & 0,218 & 0,199 \\
\hline Ácido linoleico & 2,969 & 3,559 & 3,623 \\
\hline
\end{tabular}

${ }^{1}$ Ferro (min) 60g/kg; cobre (min) 13g/kg; manganês (min) 120g/kg; zinco (min) 100g/kg; iodo (min) $2.500 \mathrm{mg} / \mathrm{kg}$; selênio (min) $500 \mathrm{mg} / \mathrm{kg}$.

${ }^{2}$ Vit. A (min) 7.500.000 UI/kg; vit. D3 (min) $2.500 .000 \mathrm{UI} / \mathrm{kg}$; vit. E (min) $1.200 \mathrm{mg} / \mathrm{kg}$; vit. K3 (min) $1.200 \mathrm{mg} / \mathrm{kg}$; tiamina $(\mathrm{min}) 1.500 \mathrm{mg} / \mathrm{kg}$; riboflavina $(\mathrm{min}) 5.500 \mathrm{mg} / \mathrm{kg}$; piridoxina $(\mathrm{min}) 2000 \mathrm{mg} / \mathrm{kg}$; vitamina B12 (min) $12.000 \mathrm{mcg} / \mathrm{kg}$; niacina $35 \mathrm{~g} / \mathrm{kg}$; panteonato de cálcio (min) $10 \mathrm{~g} / \mathrm{kg}$; biotina (min) $67 \mathrm{mg} / \mathrm{kg}$.

Os tratamentos foram: AV - dieta referência + avilamicina (controle positivo); DR - dieta referência (controle negativo); PCSc0,1 - dieta referência + parede celular de Saccharomyces cerevisiae (PCSc, 0,1\%); PCSc0,2 - dieta referência + PCSc $(0,2 \%) ; \operatorname{PCSc} 0,3$ - dieta referência + PCSc $(0,3 \%)$. O prebiótico PCSc utilizado foi o Safmannan ${ }^{\circledR}$, da empresa SAF do Brasil. As variações dos níveis da PCSc foram realizadas tendo como base a recomendação do fabricante, que é de $2 \mathrm{~kg} / \mathrm{ton}$ de ração para aves e suínos. $\mathrm{O}$ antimicrobiano utilizado no experimento foi a avilamicina, conforme modelo experimental para pesquisa e desenvolvimento de aditivos alternativos para frangos de corte descrito por Bellaver et al. (2002), que é um antimicrobiano indicado na prevenção, eminência de surto e controle de enterites necróticas provocadas por Clostridium perfringens sensíveis à avilamicina.

Devido à conhecida ação da PCSc como adsorvente de micotoxinas, foi feita uma análise micotoxicológica do milho em laboratório de micotoxicologia, segundo metodologia de Soares e Rodriguez-Amaya (1989), não sendo detectada a presença de micotoxinas. 
Foram avaliados o desempenho das aves, as características de carcaça, a metabolizabilidade das rações e a contagem de coliformes totais no íleo. As pesagens das aves foram realizadas ao início e ao final de cada período experimental. Para a avaliação de carcaça, foram abatidos dois frangos de cada unidade experimental, totalizando 12 aves por tratamento. As aves foram submetidas a um jejum de três horas antes do abate. Esse período curto de jejum foi necessário para que o conteúdo intestinal fosse suficiente para a avaliação da microbiota ileal.

Para análise da contagem de coliformes totais, fragmentos intestinais de 60 frangos foram amarrados junto ao divertículo de Meckel e na junção ileocecal, que caracteriza a porção intestinal íleo, e depois foram cortados com tesoura, de modo que as amarrações conservassem o conteúdo intestinal. Esses segmentos foram enviados para laboratório de bacteriologia veterinária, dos quais foi pesado $1 \mathrm{~g}$ de conteúdo fecal de cada íleo e transferidos para tubos de ensaio contendo $9 \mu \mathrm{L}$ de água peptonada a $0,1 \%$, e, então, realizou-se a primeira diluição, $10^{-1}$. A partir de $1 \mu \mathrm{L}$ da diluição $10^{-1}$ adicionado a $9 \mu \mathrm{L}$ de água peptonada $0,1 \%$, foi feita a segunda diluição $\left(10^{-2}\right)$, e assim sucessivamente, até a diluição $10^{-5}$. Em ágar MacConkey, $1 \mu \mathrm{L}$ das diluições de cada amostra foi inoculado em triplicata e incubado a $37^{\circ} \mathrm{C}$ por $24-48 \mathrm{~h}$. Após o período de incubação, foram feitas as contagens das unidades formadoras de colônia expressas por $\mathrm{UFCg}^{-1}$.

A metabolizabilidade dos nutrientes foi determinada apenas na fase de crescimento, utilizando-se o método de coleta total de excretas, com cinco dias para adaptação e cinco dias de coleta. As excretas foram coletadas em bandejas, revestidas com material plástico, sendo retiradas duas vezes ao dia, às oito e às 17 horas, e armazenadas em freezer. Ao término do período de coleta, foram quantificados a dieta consumida e o total das excretas por unidade experimental. Foram analisados matéria seca, energia bruta e nitrogênio das excretas e das dietas experimentais, conforme técnicas descritas por AOAC (Association..., 1990).

Com base nos resultados das análises de laboratório e dos dados de consumo de ração e de produção de excretas, foram calculados os coeficientes de metabolizabilidade aparente da matéria seca (MS) e do nitrogênio metabolizável (NM), de acordo com a fórmula descrita por Schneider e Flat (1975), bem como a energia metabolizável aparente e a energia metabolizável aparente corrigida para o balanço de nitrogênio utilizando-se as equações propostas por Matterson et al. (1965).

Os dados obtidos foram submetidos à análise de variância, utilizando-se o programa SISVAR (versão 4.3), e as médias dos tratamentos comparadas pelo teste SNK, com 5\% de probabilidade. Também foram realizadas análises de regressão segundo a inclusão de PCSc - 0,0; 0,1; 0,2 e $0,3 \%$ na ração -, sendo as estimativas de inclusão de PCSc na dieta estabelecidas, quando possível, por meio do estudo do modelo quadrático.

\section{RESULTADOS E DISCUSSÃO}

De nove a 21 dias (Tab. 2), o ganho de peso foi menor $(\mathrm{P}<0,05)$ para as aves que receberam $0,3 \%$ de parede celular de Saccharomyces cerevisiae $(\mathrm{PCSc})$. Não houve diferença significativa $(\mathrm{P}>0,05)$ para o desempenho no período de 22 a 33 dias. No período de 34 a 39 dias, o ganho de peso das aves alimentadas com $0,1 \%$ de PCSc foi superior ao das aves alimentadas com ração contendo avilamicina (AV), entretanto, na avaliação do período total de criação, não foram observados efeitos significativos $(\mathrm{P}>0,05)$.

Os resultados para o período inicial estão de acordo com os obtidos por Albino et al. (2006), que, ao utilizarem MOS, obtiveram resultados equivalentes para a inclusão de $0,2 \%$ quando comparados ao do tratamento com antimicrobiano quanto ao consumo de ração, ao ganho de peso e à conversão alimentar de frangos de corte.

Ao serem considerados os tratamentos com níveis crescentes de PCSc, observou-se efeito quadrático $(\mathrm{P}<0,05)$ da inclusão de $\mathrm{PCSc}$ sobre o ganho de peso, de acordo com a equação $\hat{\mathrm{Y}}=662,39+242,25 \mathrm{x}-1145,8 \mathrm{x}^{2} ; \mathrm{R}^{2}=0,9929$ (Fig. 1). O consumo de ração com prebiótico a $0,10 \%$ resultaria em um ganho de peso de $675 \mathrm{~g}$. 
Adição da parede celular...

Tabela 2. Consumo de ração (g), ganho de peso (g) e conversão alimentar de frangos de corte, segundo os tratamentos

\begin{tabular}{|c|c|c|c|c|c|c|}
\hline Variável & AV & DR & $\mathrm{PCSc} 0,1$ & $\mathrm{PCSc} 0,2$ & $\mathrm{PCSc} 0,3$ & $\mathrm{CV}(\%)$ \\
\hline \multicolumn{7}{|c|}{ 09-21 dias } \\
\hline Consumo de ração $(\mathrm{g})$ & 1221 & 1207 & 1218 & 1207 & 1198 & 2,00 \\
\hline Ganho de peso $(g)^{1}$ & $673 a$ & $663 a$ & $673 a$ & $667 a$ & $631 b$ & 3,47 \\
\hline Conversão alimentar & 1,82 & 1,82 & 1,81 & 1,81 & 1,90 & 3,25 \\
\hline \multicolumn{7}{|c|}{$22-33$ dias } \\
\hline Consumo de ração $(\mathrm{g})$ & 1712 & 1694 & 1763 & 1704 & 1717 & 3,87 \\
\hline Ganho de peso (g) & 1048 & 1035 & 1021 & 997 & 984 & 4,08 \\
\hline Conversão alimentar & 1,63 & 1,64 & 11,73 & 1,71 & 1,75 & 4,08 \\
\hline \multicolumn{7}{|c|}{ 34-39 dias } \\
\hline Consumo de ração $(\mathrm{g})$ & 1037 & 1058 & 1040 & 1017 & 1030 & 3,04 \\
\hline Ganho de peso (g) & $437 b$ & $450 \mathrm{ab}$ & $461 \mathrm{a}$ & $456 \mathrm{ab}$ & $458 \mathrm{ab}$ & 2,89 \\
\hline Conversão alimentar & 2,37 & 2,35 & 2,26 & 2,23 & 2,25 & 4,10 \\
\hline \multicolumn{7}{|c|}{ 09-39 dias } \\
\hline Consumo de ração $(\mathrm{g})$ & 3970 & 3959 & 4021 & 3927 & 3945 & 2,30 \\
\hline Ganho de peso (g) & 2158 & 2148 & 2156 & 2119 & 2073 & 2,39 \\
\hline Conversão alimentar & 1,84 & 1,84 & 1,86 & 1,85 & 1,90 & 2,04 \\
\hline
\end{tabular}

Médias seguidas de letras diferentes na linha diferem entre si pelo teste $\mathrm{SNK}(\mathrm{P}<0,05)$. ${ }^{\mathrm{E}}$ Efeito quadrático da inclusão de PCSc $(\mathrm{P}<0,05) ; \mathrm{AV}$ - dieta referência + avilamicina; DR - dieta referência; PCSc 0,1 - dieta referência $+0,1 \%$ de $\mathrm{PCS} c$; PCSc 0,2 - dieta referência $+0,2 \%$ de PCSc; PCSc 0,3 - dieta referência + 0,3\% de PCSc.

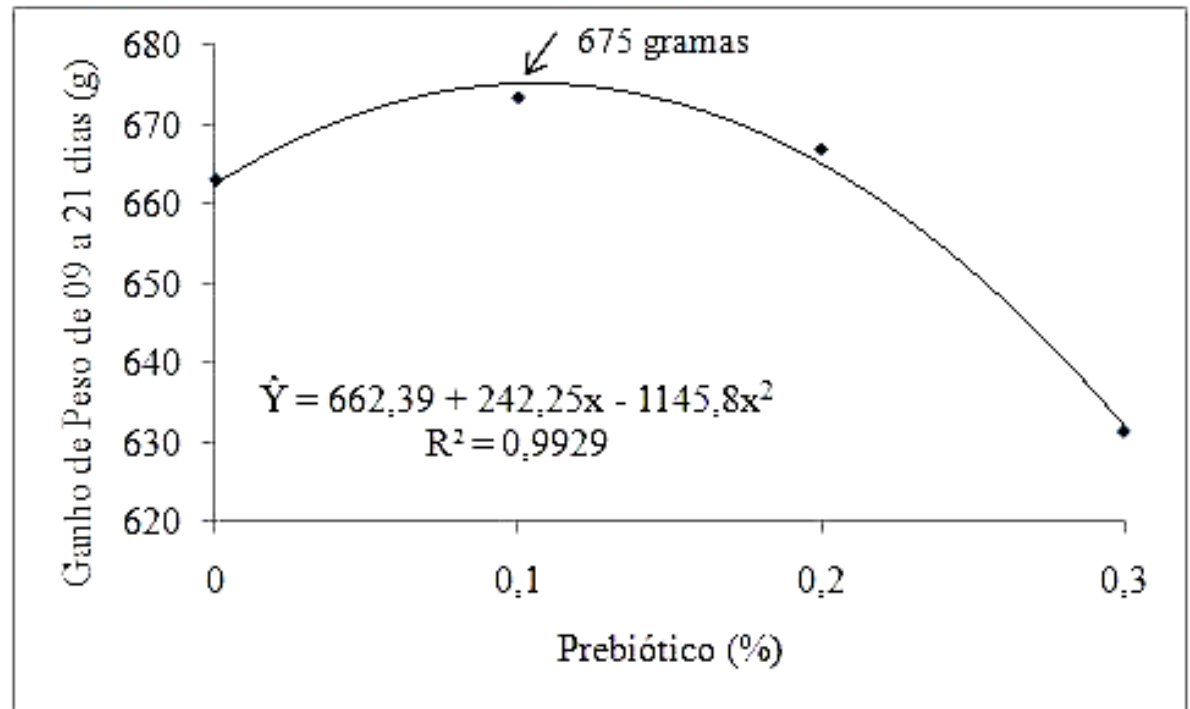

Figura 1. Ganho de peso de frangos de corte aos 21 dias de idade, segundo a inclusão de prebiótico.

No período de crescimento, não houve diferenças entre os tratamentos estudados. Isto poderia ser explicado, em parte, pelas boas condições de alojamento, sanidade e manejo a que as aves foram submetidas neste trabalho e pela criação em gaiolas, que podem ter colaborado para um menor desafio sanitário. Pesquisadores têm obtido respostas similares com o uso de diferentes prebióticos e controle positivo - com antimicrobiano - na dieta e até mesmo com o controle negativo - dieta sem antimicrobiano sobre o desempenho geral de frangos de corte (Dionizio et al., 2002; Baurhoo et al., 2009). 
No período final, os frangos alimentados com dieta contendo AV apresentaram menor ganho de peso do que os que receberam $0,1 \%$ de PCSc na ração, porém não diferiram dos ganhos observados nos demais tratamentos. Este resultado pode indicar ser vantajosa a adição de $0,1 \%$ de PCSc na ração de frangos de corte.

No período total, não foram observados efeitos significativos $(\mathrm{P}>0,05)$ entre os diferentes tratamentos sobre o desempenho, estando os valores próximos aos propostos para a linhagem Hubbard (Hubbard Classic, 2010). Os resultados estão de acordo com os encontrados por Baurhoo et al. (2009), que, ao utilizarem dois níveis de MOS e antimicrobianos, não observaram diferenças entre os tratamentos ao avaliarem o desempenho de frangos de corte até 35 dias de idade. Os autores atribuíram essa resposta à ausência de desafio sanitário às aves. Ainda, para o período total, os resultados diferem dos observados por Santin et al. (2001), que, ao utilizarem dietas sem PCSc, com 0,1 e $0,2 \%$ de PCSc, observaram melhora no ganho de peso, no período de um a 42 dias de idade, com a dieta contendo $0,2 \%$ de PCSc.

Observou-se efeito significativo $(\mathrm{P}<0,05)$ dos tratamentos para viabilidade (Tab. 3), sendo que os frangos que consumiram a DR apresentaram uma menor viabilidade do que os frangos que receberam AV e PCSc no período de 22 a 33 dias, independentemente do nível de inclusão. Isso mostra a necessidade de inclusão de um aditivo zootécnico na ração para a manutenção da saúde dos frangos, uma vez que a inclusão de PCSc resultou em maior viabilidade e, assim, garantiu resultados comparáveis aos de frangos que receberam AV, que é um aditivo melhorador de desempenho.

Tabela 3. Percentual de viabilidade nos diferentes períodos de idade de frangos de corte, segundo os tratamentos

\begin{tabular}{ccccccc}
\hline Período (dias) & AV & DR & PCSc0,1 & PCSc0,2 & PCSc0,3 & CV (\%) \\
\hline 9 a 21 & 98,33 & 100 & 98,33 & 100 & 98,33 & 3,19 \\
22 a 33 & $100 \mathrm{a}$ & $93,33 \mathrm{~b}$ & $100 \mathrm{a}$ & $100 \mathrm{a}$ & $100 \mathrm{a}$ & 3,82 \\
34 a 39 & 98,17 & 95,83 & 98,33 & 98,33 & 98,33 & 4,58 \\
9 a 39 & 96,67 & 89,33 & 96,67 & 98,33 & 96,67 & 6,91 \\
\hline
\end{tabular}

Médias com letras diferentes na mesma linha diferem entre si pelo teste SNK $(\mathrm{P}<0,05)$. AV - dieta referência + avilamicina; DR - dieta referência; PCSc 0,1 - dieta referência $+0,1 \%$ de PCSc; PCSc 0,2 - dieta referência $+0,2 \%$ de $\mathrm{PCS} c$; PCSc 0,3 - dieta referência + 0,3\% de PCSc.

Segundo Silva e Nönberg (2003), se os animais não estão em condições estressantes supõe-se que a microbiota esteja em equilíbrio, não sendo significante o uso ou não de prebióticos na dieta, pois as respostas obtidas seriam semelhantes com ou sem eles. Já em condições de estresse temperaturas elevadas, superpopulação, desafio sanitário -, o uso do prebiótico poderia se mostrar benéfico, resultando em melhor resposta biológica. No presente experimento, as aves foram submetidas a condições de temperatura natural, em que foram registradas médias acima da temperatura de conforto térmico $\left(26,58^{\circ} \mathrm{C}\right)$ e especialmente temperaturas mínimas $\left(25,20^{\circ} \mathrm{C}\right)$ já próximas da temperatura considerada de estresse térmico para frangos de corte.
Em relação ao peso vivo pós-jejum, os frangos alimentados com PCSc0,1 apresentaram maior valor (Tab. 4), enquanto os frangos alimentados com PCSc0,3 tiveram menor valor, e aqueles alimentados com AV, PCSc0,1 e PCSc0,2 tiveram valores intermediários. Os frangos alimentados com PCSc0,1 e PCSc0,2 tiveram maior peso absoluto de sobrecoxa e coxa+sobrecoxa $(\mathrm{P}<0,05)$ em relação àqueles alimentados com $\mathrm{PCS} C 0,3$, porém não apresentaram média de peso absoluto de sobrecoxa $(\mathrm{P}>0,05)$, diferentemente daqueles que receberam AV e DR. Os resultados obtidos quanto aos rendimentos estão de acordo com Santos et al. (2005) e Godoi et al. (2008), com utilização de MOS para rendimento de carcaça e de peito. 
Adição da parede celular...

Tabela 4. Características de carcaça de frangos de corte abatidos aos 40 dias de idade, segundo os tratamentos

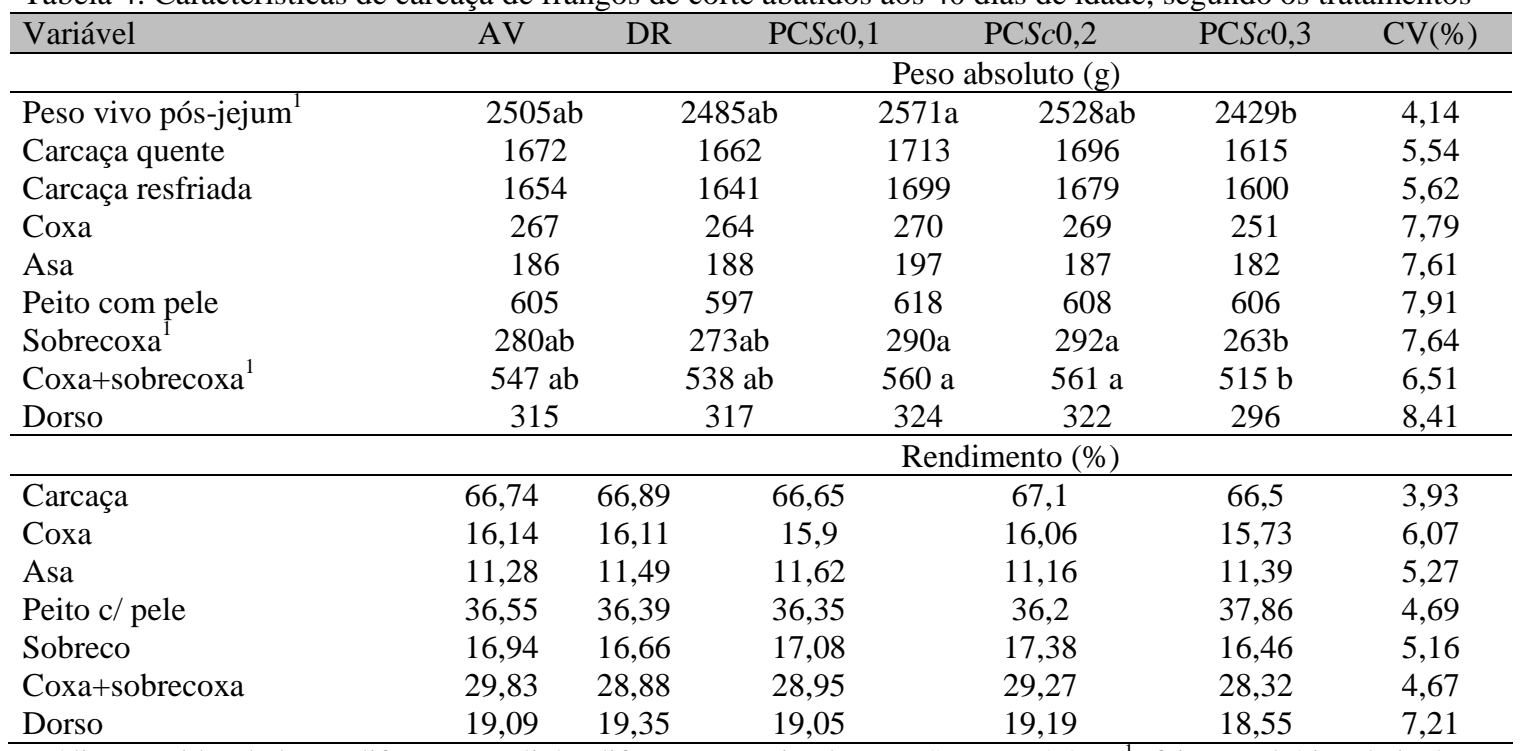

Médias seguidas de letras diferentes na linha diferem entre si pelo teste $\mathrm{SNK}(\mathrm{P}<0,05)$. ${ }^{\mathrm{I}}$ Efeito quadrático da inclusão de PCSc $(\mathrm{P}<0,05)$. AV - dieta referência + avilamicina; DR - dieta referência; PCSc 0,1 - dieta referência $+0,1 \%$ de $\mathrm{PCSc}$; PCSc 0,2 - dieta referência $+0,2 \%$ de PCSc; PCSc0,3 - dieta referência + 0,3\% de PCSc.

Observou-se efeito quadrático da inclusão de PCSc sobre o peso vivo pós-jejum $(\hat{\mathrm{Y}}=2488,2+$ $\left.1181,3 \mathrm{x}-4633,3 \mathrm{x}^{2} ; \quad \mathrm{R}^{2}=0,9766\right)$, o peso absoluto de sobrecoxa $(\hat{\mathrm{Y}}=272,72+308,08 \mathrm{x}-$ $1120,8 \mathrm{x}^{2} ; \mathrm{R}^{2}=0,9783$ ) e o peso absoluto de coxa+sobrecoxa $(\hat{\mathrm{Y}}=536,49+446,58 \mathrm{x}-$ $\left.1712,5 \mathrm{x}^{2} ; \mathrm{R}^{2}=0,9749\right)$. Com prebiótico de $0,13 \%$ seria obtido o peso vivo pós-jejum máximo de $2563 \mathrm{~g}$. Para inclusões acima desse valor, o peso vivo pós-jejum diminuiria.

O peso máximo absoluto de sobrecoxa de $294 \mathrm{~g}$ seria obtido com a adição de $0,14 \%$ de prebiótico. Da mesma forma, o peso máximo absoluto de coxa+sobrecoxa de 566g seria obtido com a inclusão de $0,13 \%$ de PCSc. A partir desse valor, o aumento de PCSc resultaria em diminuição do peso absoluto de coxa+sobrecoxa.

Considerando as análises de regressão, pode-se presumir que a inclusão de PCSc nos valores de 0,13 ou $0,14 \%$ seria suficiente para assegurar o maior ganho de peso desses cortes, suposição que poderia ser melhor analisada em experimentos com animais em condições de criação comercial, cuja resposta da utilização do prebiótico provavelmente seria mais evidente. Os efeitos dos resultados para o teste de médias foram suficientes para se refletir nos efeitos observados nas análises de regressão citadas.
Não foram observados efeitos significativos $(\mathrm{P}>0,05)$ da adição de AV e de PCSc em relação à DR sobre o peso relativo e absoluto das vísceras e da gordura abdominal dos frangos (Tab. 5), seja para peso absoluto, seja para seu peso relativo, considerando todos os tratamentos ou entre as porcentagens de inclusão de PCSc, resultados que corroboram aqueles observados por Godoi et al. (2008) em relação ao peso relativo da bursa e à utilização de MOS. A utilização de PCSc garantiu resultados comparáveis aos dos frangos que receberam dieta contendo o antimicrobiano avilamicina.

Observou-se que a inclusão de AV e de PCSc não modificou $(\mathrm{P}>0,05)$ a contagem bacteriana no íleo (Tab. 6), em comparação à dieta referência, o que sugere que a contagem total de coliformes totais não foi alterada. Jin et al. (1998), ao trabalharem com culturas de Lactobacillus na dieta de frangos de corte, obtiveram resultados na contagem total bacteriana com média próxima àquela encontrada neste estudo, e também não foram encontradas diferenças entre os tratamentos. Os resultados encontrados neste experimento diferem dos relatados por Santos et al. (2005), que avaliaram a utilização de antibiótico e de outros aditivos para frangos de corte $\mathrm{e}$ observaram diferenças entre os tratamentos para a contagem total de bactérias. 
Tabela 5. Peso absoluto e relativo das vísceras, da gordura abdominal, do baço e da bursa de fabrícius

\begin{tabular}{lcccccc}
\hline Variável & AV & DR & PCSc0,1 & PCSc0,2 & PCSc0,3 & CV $(\%)$ \\
\hline Gordura & \multicolumn{5}{c}{ Peso absoluto $(\mathrm{g})$} \\
Moela & 24,27 & 27,46 & 23,67 & 25,27 & 18,36 & 34,68 \\
Fígado & 35,01 & 32,06 & 31,82 & 33,23 & 31,33 & 13,97 \\
Coração & 44,61 & 44,9 & 48,11 & 47,79 & 45,88 & 13,01 \\
Baço & 11,31 & 11,90 & 11,40 & 11,56 & 11,00 & 12,37 \\
Bursa & 2,84 & 2,92 & 2,92 & 3,12 & 2,45 & 21,47 \\
\hline & 1,77 & 2,11 & 2,07 & 2,02 & 1,92 & 24,96 \\
\hline Gordura & 1,47 & 1,66 & 1,40 & 1,51 & 1,15 & 33,29 \\
Moela & 2,13 & 1,96 & 1,87 & 1,98 & 1,97 & 15,00 \\
Fígado & 2,70 & 2,75 & 2,83 & 2,84 & 2,88 & 13,63 \\
Coração & 0,68 & 0,73 & 0,67 & 0,69 & 0,69 & 13,94 \\
Baço & 0,17 & 0,18 & 0,17 & 0,19 & 0,15 & 21,46 \\
Bursa & 0,11 & 0,13 & 0,12 & 0,12 & 0,12 & 24,51 \\
\hline
\end{tabular}

Médias iguais na linha pelo teste SNK $(\mathrm{P}>0,05)$. AV - dieta referência + avilamicina; DR - dieta referência; $\mathrm{PCSc0,1}$ - dieta referência $+0,1 \%$ de PCSc; PCSc 0,2 - dieta referência $+0,2 \%$ de PCSc; PCSc 0,3 - dieta referência $+0,3 \%$ de PCSc.

Tabela 6. Contagem de coliformes totais (unidades formadoras de colônias - UFC) do íleo de frangos de corte abatidos aos 40 dias de idade

\begin{tabular}{lcccccc}
\hline Variável & AV & DR & PCSc0,1 & PCSc0,2 & PCSc0,3 & CV (\%) \\
\hline $\begin{array}{l}\text { Íleo (Log } \\
\text { UFC/g) }\end{array}$ & 6,55 & 6,31 & 6,87 & 6,26 & 5,56 & 25,75 \\
\hline
\end{tabular}

Médias iguais na linha pelo teste SNK $(\mathrm{P}>0,05)$. AV - dieta referência + avilamicina; DR - dieta referência; PCSc0,1 - dieta referência $+0,1 \%$ de PCSc; PCSc 0,2 - dieta referência $+0,2 \%$ de PCSc; PCSc 0,3 - dieta referência $+0,3 \%$ de PCSc.

O fato de não ocorrer alteração na contagem de UFC pela presença de AV e de PCSc não significa que estes não tenham causado mudanças, mas pode ser explicado pelas condições em que os animais foram criados, em ambiente limpo e com pouco estresse, em que não houve aumento bacteriano suficiente para causar desequilíbrio.

Não foram observados efeitos significativos $(\mathrm{P}>0,05)$ de $\mathrm{AV}$ e de PCSc para CMMS, CMN,
EMA e EMAn (Tab. 7). Oliveira et al. (2007), ao trabalharem com MOS e complexo enzimático para frangos de corte, observaram que os valores obtidos para as aves alimentadas com dietas contendo complexo enzimático e/ou MOS foram mais altos para coeficiente de digestibilidade da MS quando comparados aos valores para frangos alimentados com dietas contendo antimicrobianos.

Tabela 7. Coeficiente de metabolizabilidade da matéria seca (CMMS), do nitrogênio (CMN), da energia metabolizável aparente (EMA) e da energia metabolizável aparente corrigida para o balanço de nitrogênio (EMAn) das dietas experimentais

\begin{tabular}{lcccccc}
\hline Variável & AV & DR & PCSc0,1 & PCSc0,2 & PCSc0,3 & CV $(\%)$ \\
\hline CMMS (\%) & 70,60 & 69,74 & 70,16 & 71,03 & 71,66 & 3,39 \\
CMN (\%) & 58,90 & 58,06 & 60,02 & 60,24 & 62,11 & 6,20 \\
EMA (Kcal/kg) & 2927 & 2795 & 2855 & 2855 & 2841 & 3,65 \\
EMAn (Kcal/kg) & 2751 & 2630 & 2676 & 2682 & 2652 & 3,51 \\
\hline
\end{tabular}

Médias iguais na linha pelo teste SNK (P>0,05). AV - dieta referência + avilamicina; DR - dieta referência; PCSc0,1 - dieta referência $+0,1 \%$ de PCSc; PCSc 0,2 - dieta referência $+0,2 \%$ de PCSc; PCSc 0,3 - dieta referência $+0,3 \%$ de PCSc. 
Rizzo et al. (2010), ao utilizarem extratos vegetais em dietas para frangos de corte e avaliarem EMAn e digestibilidade da $\mathrm{PB}$, não encontraram diferenças atribuídas aos tratamentos, o que sugere que a ausência de resposta poderia estar relacionada à ausência de desafio na criação e à utilização de ingredientes de alta digestibilidade, pois estes dificultam a detecção de resultados superiores, que seriam possivelmente causados pela inclusão de aditivos melhoradores do desempenho. As dietas utilizadas no presente experimento foram à base de milho e farelo de soja, que são ingredientes de alta digestibilidade, o que pode, em parte, ter contribuído para a observação de resultados não significativos para todos os parâmetros de metabolizabilidade estudados.

\section{CONCLUSÕES}

Dietas de frangos de corte nas quais a parede celular de Saccharomyces cerevisiae foi incluída em valores de até $0,2 \%$ resultaram em índices produtivos adequados e, portanto, podem ser utilizadas como aditivo em dietas livres de antimicrobiano melhorador de desempenho sem comprometimento do desempenho, das características de carcaça, da metabolizabilidade da ração e da contagem total de coliformes totais do íleo de frangos de corte.

\section{AGRADECIMENTOS}

Os autores agradecem à Capes, pelo suporte financeiro para a publicação deste artigo, e à empresa SAF do Brasil, pelo fornecimento da parede celular de Saccharomyces cerevisiae.

\section{REFERÊNCIAS}

ALBINO, L.F.T.; FERES, F.A.; DIONIZIO, M.A. et al. Uso de prebióticos à base de mananoligossacarídeos em dietas para frangos de corte. Rev. Bras. Zootec., v.35, p.742-749, 2006.

ASSOCIATION of official analitical chemists AOAC. Official methods of analysis. 15.ed. Arlington, 1990. 1230p.

BAURHOO, B.; FERKET, P.R.; ZHAO, X. Effects of diets containing different concentrations of mannanoligosaccharide or antibiotics on growth performance, intestinal development, cecal and litter microbial populations, and carcass parameters of broilers. Poult. Sci., v.88, p.2262-2272, 2009.
BELLAVER, C.; COSTA, C.A.F.; MACHADO, H.G.P.; LIMA, G.J.M.M. Modelo Experimental para Pesquisa e Desenvolvimento de Aditivos Alternativos para Frangos de Corte. Concórdia: Embrapa Suínos e Aves. 2002. 3p.

COMPÊNDIO brasileiro de alimentação animal. 3.ed. São Paulo: Sindirações. 2009. 390 p.

DIONIZIO, M.A.; BERTECHINI, A.G.; KATO, R.K.; TEIXEIRA, A.S. Prebióticos como promotores de crescimento para frangos de corte - Desempenho e rendimento de carcaça. Cienc. Agrotec., Edição especial, p.1580-1587, 2002.

FERREIRA, D.F. Sisvar: Sistema de análise estatística para dados balanceados, versão 4.3. Lavras: UFLA/DEX, 2003.

GODOI, M.J.S.; ALBINO, L.F.T.; ROSTAGNO, H.S. et al. Utilização de aditivos em dietas formuladas com milho normal e de baixa qualidade para frangos de corte. Rev. Bras. Zootec., v.37, p.1005-1011, 2008

HUBBARD CLASSIC. Quadro de resultados de frangos de corte Hubbard. Disponível em: <http://hubbardbreeders.com/managementgu ides/ index.php?id=13>. Acessado em: 1 nov. 2010.

JIN, L.Z.; HO, Y.W.; ABDULLAH, N.; JALALUDIN, S. Growth performance, intestinal microbial populations, and serum cholesterol of broilers fed diets containing lactobacillus cultures. Poult. Sci., v.77, p.1259-1265, 1998.

KLIS, F.M.; MOL. P.; HELLINGWERF, K.; BRUL. $\mathrm{S}$. Dynamics of cell wall structure in Saccharomyces cerevisiae. Microbiol. Rev., v.26, p.239-256, 2002.

LIPKE, P.N.; OVALLE, R. Cell wall arquitecture in yeast: new structure and new challenges. J. Bact., v.180, p.3735-3740, 1998.

MATTERSON, L.D.; POTTER, L.M.; STUTZ, N.W.; SINGSEN, E.P. The metabolizable energy feed ingredients for chickens. Storrs: University of Connecticut, 1965.11p.

OLIVEIRA, M.C.; CANCHERINI, L.C.; GRAVENA, R.A. et al. Utilização de nutrientes de dietas contendo mananoligossacarídeos e/ou complexo enzimático para frangos de corte. Rev. Bras. Zootec., v.36, p.825-831, 2007.

RIZZO, P.V.; MENTEN, J.F.M.; RACANICCI, A.M.C. et al. Extratos vegetais em dietas para frangos de corte. Rev. Bras. Zootec., v.39, p.801-807, 2010.

ROSTAGNO, H.S.; ALBINO, L.F.T.; DONZELE, J.L. et al. Tabelas Brasileiras para Aves e Suínos: composição de alimentos e exigências nutricionais. 2.ed. Viçosa: Universidade Federal de Viçosa, 2005. $186 \mathrm{p}$. 
SANTIN, E.; MAIORKA, A.; MACARI, M Performance and intestinal mucosa development of broiler chickens fed diets containing Saccharomyces cerevisiae cell wall. J. Appl. Poult. Res., v.10, p.236244, 2001.

SANTOS, E.C.; TEIXEIRA, A.S.; FREITAS, R.T.F. et al. Uso de aditivos promotores de crescimento sobe o desempenho, características de carcaça e bactérias totais do intestino de frangos de corte. Rev. Cienc. Agrotec., v.29, p.223-231, 2005.

SCHNEIDER, B.A.; FLAT, W.P. The eval of feeds through digest exper. Athens: The University of Georgia, 1975. 423p.
SHAW, J.A.; MOL., P.C.; BOWERS, B. et al. The function of chitin synthases 2 and 3 in the Saccharomyces cerevisiae cell cycle. J. Cell Biol., v.114, p.111-123, 1991.

SILVA, L.P.; NÖRNBERG, J.L. Prebióticos na nutrição de não ruminantes. Cienc. Rural, v.33, p.983990, 2003.

SOARES, L.M.V.; RODRIGUEZ-AMAYA, D.B. Survey of aflatoxins, ochratoxins A, zearalenona and sterigmatocystin in some Brazilian foods by multitoxin thin layer chromatographic method. $J$. Assoc. Offic. Anal. Chem., v.72, p.22-26, 1989. 